\title{
Experimental investigation of machinability and microstructure analysis on Inconel 718
}

\author{
T. Mugilan ${ }^{1}$, S. Santhosh ${ }^{2}$, N. Sridhar ${ }^{3}$ \\ ${ }^{1,2}$ P.G.Scholar, Department of Engineering Design, \\ Government college of Technology, Coimbatore-13, Tamilnadu - India. \\ ${ }^{3}$ Assistant Professor, Department of Mechanical Engineering, \\ Karpagam Institute of Technology, Coimbatore-13, Tamilnadu - India. \\ Email: mugilanapec@gmail.com ${ }^{1}, \underline{\text { santhoshsivaklm@gmail.com }}$, sridharmech083@gmail.com $^{3}$
}

\begin{abstract}
In this work, Inconel 718 nickel-based alloy was chosen for analyses the machinability and microstructure. CNC turning center was used for conducting the experimental work based on the L9 orthogonal array on heat treated and non-heat-treated material. The design of experiment is performed by using MINITAB 17 statistical software tool. From the experiment material removal rate and surface characteristics was computed in order to conclude the machinability of the nickel-based alloy. Both the results obtained from heated and nonheated materials were compared and evaluated. The microstructure of the heat treated and non-heat-treated nickel-based alloy material was analyzed with help of scanning electron microscope.
\end{abstract}

Index Terms- Machinability; Inconel 718; micro structure; surface roughness; material removal rate;

\section{INTRODUCTION}

Machining is one of the manufacturing processes. The process of removing material is called machining. The setup cost of this process is low compared to molding and casting. For tight tolerance and good surface finish required machining process. Turning is another basic machining processes. Turning is defined as reducing the diameter of the material. during turning processes, the workpiece is rotating, and tool is fixed in the lathe. Lathes are designed for turning operations, in this process tight tolerance is achieved. The chuck in lathe holding the workpiece which is rotated with respect to stationary tool.

Machinability of nickel based super - alloys is extremely poor, mainly due to their low thermal conductivity, build up edge and self-hardening, which leads to high dynamic cutting forces. Due to these factors the tool wear is extremely high and increasing the tool life by minutes is an enormous success. The greatest problem in machining these materials is the heat stress. An extreme heat load is applied to the tools and the plastic deformation of the cutting edge may be observed.

Jawaid [1] Nickel-based super alloys have been widely used in the aircraft and nuclear industry due to their exceptional thermal resistance and the ability to retain mechanical properties at elevated temperatures. Hasimoto [2] the microstructural evaluation in Inconel 718 were investigated in both solutions annealed (SA) and precipitation hardened $(\mathrm{PH})$ condition. Soo [3] The development of a 3D finite element model for the turning of Inconel 718 using ABAQUS as per cursor to ball end milling simulation. Arunachalam [4] this paper focuses on the residual stresses and surface roughness aspects of surface integrity in the facing operation of Inconel 718 using $\mathrm{CBN}$ and mixed ceramic cutting tools. Pawade [5] the quality of machined surface and subsurface during high speed machining of Inconel 718 is necessary so as to achieve component with greater reliability and longevity. Courbon [6] machining the Inconel 718 with coated carbide insert in the most aggressive cutting conditions, using 20.3MPa coolant pressure. Abdullah Kurt, [7] in this paper, the cutting tool stresses (normal, shear and von misses) in machining of nickel-based super alloy Inconel 718 have been investigated. Tabernero [8] Nickel alloy containing significant amount of element that include Iron, Chromium, Molybdenum, and Niobium, among others.

The detailed study of literature reveals the following problem identifications. The nickel based super alloy like Inconel, ivory, monel, nicrofer, nimonic are investigated in the past years, but even there is some gap in the research are identified and put forth to investigate. The Inconel alloy are difficult to machine due to the hardness, hence because of the strength ratio is less reach area. The microstructure analysis of nickel alloys shows that the strong adhesive nature with Iron-Carbon region, hence the study of optical diffraction is very less in microstructural analysis. These information about the materials are not accurate, description in the function of strain rate, temperature and other parameters. There is no proper iterative convergent procedures was employed to improve Finite Element (FE) prediction.

The objective of the present study investigates the following aspect, to evaluate machinability index for the hard material as Inconel 718. The material hardness increases with help of the heat treatment and evaluate the machinability of the material. The adhesive of the Inconel material is to increase by the process of heating, and it is analyzed by 


\section{Available online at www.ijrat.org}

microstructure. To determine the accurate value of stress \& strain rate, temperature, displacement and velocity of the nickel alloy Inconel 718 . To evaluate a proper iterative convergent procedure to improve the Finite Element (FE) prediction.

\section{MATERIALS AND METHODOLOGY}

\subsection{Work piece material}

INCONEL alloy 718 (UNS N07718/W.Nr. 2.4668) is a high-strength, corrosion-resistant nickel chromium material used at $-423^{\circ}$ to $1300^{\circ} \mathrm{F}$. Typical composition limits are shown in Table 1.

Table 1. Chemical composition of Inconel 718

\begin{tabular}{|c|c|c|c|}
\hline Elements & \% & Elements & \% \\
\hline $\mathrm{Ni}$ & $50.00-55.00$ & $\mathrm{Al}$ & $0.20-0.80$ \\
\hline $\mathrm{Cr}$ & $17.00-21.00$ & $\mathrm{Co}$ & $1.00 \max$ \\
\hline $\mathrm{Nb}$ & $4.75-5.50$ & $\mathrm{Cr}$ & $0.08 \max$ \\
\hline $\mathrm{Mo}$ & $2.80-3.30$ & $\mathrm{Mn}$ & $0.35 \max$ \\
\hline $\mathrm{Ti}$ & $0.65-1.15$ & $\mathrm{Si}$ & $0.35 \max$ \\
\hline $\mathrm{P}$ & $0.015 \max$ & $\mathrm{B}$ & $0.006 \max$ \\
\hline $\mathrm{S}$ & $0.015 \max$ & $\mathrm{Cu}$ & $0.30 \max$ \\
\hline
\end{tabular}

\subsection{Cutting insert}

The tool opted for experimental purpose is coated carbide tool insert whose specification is TN2000 04. The following figure represents the carbide insert. The coatings offer high speed capability. TN2000 is an ideal grade for machining of workpiece. Tool insert is coated on two sides shown in figure 1; hence machining can be done on both sides. TN2000 provides improved impact resistance, at the time of machining. So that the tool insert possesses extended working life.

\subsection{Experimental procedure}

Taguchi $\mathrm{L}_{9} \mathrm{OA}$ was used as design of experiment with
ted and un heat treated was carried with help of heated and un heat treated was carried with help of
scanning electron microscope. The CNC turning center as shown in figure 1. This type of turning centres are widely suitable to machining the hardened material. It also used for high speed turning machining purpose to yield the maximum production rate and minimize the machining time. The surface characteristics of machined material is measured with aid of surface roughness tester. With aid of Muffle furnace material was treated with appropriate temperature. Muffle furnace shown in figure 2.

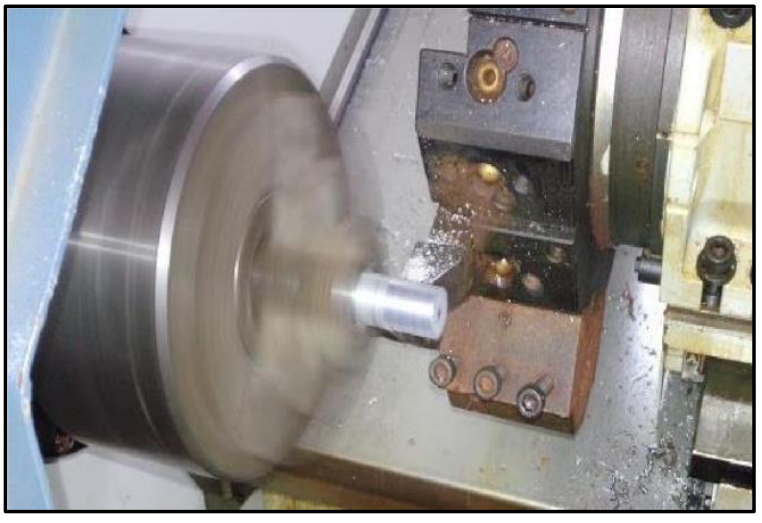

Fig 1. CNC turning center

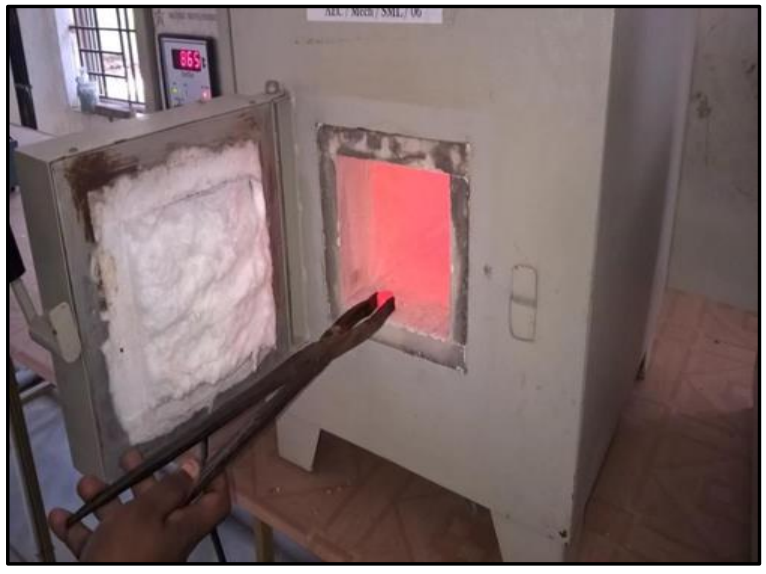

Fig 2. Muffle furnace

\section{EXPERIMENTAL DESIGN AND PREDICTED VALUES}

The magnitude of design parameters corresponds to different levels are shown in table 2. Three levels were given to machining parameter based on Experimental design and is analyzed to through ANOVA. The experimental plan encloses nine

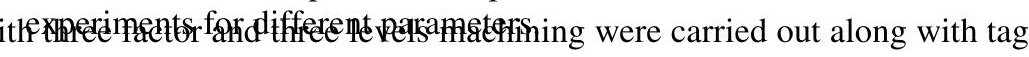
Table 2. Machining parameters and levels

\begin{tabular}{|c|c|c|c|}
\hline Parameter & Level 1 & Level 2 & Level 3 \\
\hline Speed (rpm) & 700 & 800 & 900 \\
\hline Feed (mm/rev) & 0.20 & 0.25 & 0.30 \\
\hline Depth of cut (mm) & 0.50 & 0.75 & 1.00 \\
\hline
\end{tabular}

By using statistical tool (MINITAB 17), experimental design was done which is used to conduct the experiment with effective manner at different levels and various input cutting parameters. This type of design experiments gives controlled output values and gives the required information about objective. The following table 3 . depicts the $\mathrm{L}_{9}$ Orthogonal Array. 


\section{Available online at www.ijrat.org}

Table 3. L 9 Orthogonal Array

\begin{tabular}{|c|c|c|c|}
\hline S.NO & $\begin{array}{c}\text { Speed } \\
(\mathbf{r p m})\end{array}$ & $\begin{array}{c}\text { Feed } \\
(\mathbf{m m} / \mathbf{r e v})\end{array}$ & $\begin{array}{c}\text { Depth of } \\
\text { cut }(\mathbf{m m})\end{array}$ \\
\hline 1. & 700 & 0.20 & 0.50 \\
\hline 2. & 700 & 0.25 & 0.75 \\
\hline 3. & 700 & 0.30 & 1.00 \\
\hline 4. & 800 & 0.20 & 0.75 \\
\hline 5. & 800 & 0.25 & 1.00 \\
\hline 6. & 800 & 0.30 & 0.50 \\
\hline 7. & 900 & 0.20 & 1.00 \\
\hline 8. & 900 & 0.25 & 0.50 \\
\hline 9. & 900 & 0.30 & 0.75 \\
\hline
\end{tabular}

Surface roughness and material removal rate of the non Table 4. Ra and MRR for non-heat-treated material

\begin{tabular}{|c|c|c|c|c|c|}
\hline S.NO & $\begin{array}{r}\text { Speed } \\
(\mathbf{r p m})\end{array}$ & $\begin{array}{c}\text { Feed } \\
(\mathbf{m m} / \mathbf{r e v})\end{array}$ & $\begin{array}{c}\text { Depth } \\
\text { of cut } \\
(\mathbf{m m})\end{array}$ & $\begin{array}{c}\mathbf{R}_{\mathbf{a}} \\
(\boldsymbol{\mu m})\end{array}$ & $\begin{array}{c}\text { MRR } \\
\left(\mathbf{m m}^{\mathbf{3}} / \mathbf{s e c}\right)\end{array}$ \\
\hline $\mathbf{1 .}$ & 700 & 0.20 & 0.50 & 1.76 & 36.17 \\
\hline $\mathbf{2 .}$ & 700 & 0.25 & 0.75 & 1.89 & 67.40 \\
\hline $\mathbf{3 .}$ & 700 & 0.30 & 1.00 & 2.35 & 107.77 \\
\hline $\mathbf{4 .}$ & 800 & 0.20 & 0.75 & 2.97 & 61.62 \\
\hline $\mathbf{5 .}$ & 800 & 0.25 & 1.00 & 3.26 & 102.07 \\
\hline $\mathbf{6 .}$ & 800 & 0.30 & 0.50 & 2.07 & 62.003 \\
\hline $\mathbf{7 .}$ & 900 & 0.20 & 1.00 & 1.83 & 91.866 \\
\hline $\mathbf{8 .}$ & 900 & 0.25 & 0.50 & 2.85 & 58.136 \\
\hline $\mathbf{9 .}$ & 900 & 0.30 & 0.75 & 3.16 & 103.999 \\
\hline
\end{tabular}

Surface roughness and material removal rate of the heat-treated Inconel 718 nickel-based alloy was measured from the experiment conducted on $\mathrm{CNC}$ turning center based on DOX is shown in the following table 4.

Table 5. Ra and MRR for heat-treated material

\begin{tabular}{|c|c|c|c|c|c|}
\hline S.NO & $\begin{array}{c}\text { Speed } \\
(\mathbf{r p m})\end{array}$ & $\begin{array}{c}\text { Feed } \\
(\mathbf{m m} / \mathbf{r e v})\end{array}$ & $\begin{array}{c}\text { Depth } \\
\mathbf{o f} \mathbf{c u t} \\
(\mathbf{m m})\end{array}$ & $\begin{array}{c}\mathbf{R}_{\mathbf{a}} \\
(\boldsymbol{\mu \mathbf { m }})\end{array}$ & $\begin{array}{c}\text { MRR } \\
\left(\mathbf{m m}^{\mathbf{3}} / \mathbf{s e c}\right)\end{array}$ \\
\hline $\mathbf{1 .}$ & 700 & 0.20 & 0.50 & 2.72 & 45.92 \\
\hline $\mathbf{2 .}$ & 700 & 0.25 & 0.75 & 3.56 & 86.95 \\
\hline $\mathbf{3 .}$ & 700 & 0.30 & 1.00 & 3.98 & 100.92 \\
\hline $\mathbf{4 .}$ & 800 & 0.20 & 0.75 & 3.15 & 75.95 \\
\hline $\mathbf{5 .}$ & 800 & 0.25 & 1.00 & 3.96 & 98.26 \\
\hline $\mathbf{6 .}$ & 800 & 0.30 & 0.50 & 4.53 & 90.85 \\
\hline $\mathbf{7 .}$ & 900 & 0.20 & 1.00 & 2.95 & 101.82 \\
\hline $\mathbf{8 .}$ & 900 & 0.25 & 0.50 & 3.62 & 62.35 \\
\hline $\mathbf{9 .}$ & 900 & 0.30 & 0.75 & 4.82 & 112.567 \\
\hline
\end{tabular}

\section{RESULT AND DISCUSSION}

\subsection{Comparison study}

The validated results are compared between the heated and non-heated Inconel 718 nickel-based alloy. The comparison is done for various measured roughness of a surface and material removal rate are represented in the table 6 .

Table 6. Comparison between treated and untreated material of Inconel 718

\begin{tabular}{|c|c|c|c|c|}
\hline & \multicolumn{2}{|c|}{$\begin{array}{c}\text { Non-heat-treated } \\
\text { material }\end{array}$} & \multicolumn{2}{c|}{ Heat-treated material } \\
\hline S.NO & $\begin{array}{c}\text { Surface } \\
\text { Roughness } \\
\left(\mathbf{R}_{\mathrm{a}}\right)\end{array}$ & $\begin{array}{c}\text { Metal } \\
\text { removal } \\
\text { rate }\end{array}$ & $\begin{array}{c}\text { Surface } \\
\text { Roughness } \\
\left(\mathbf{R}_{\mathrm{a}}\right)\end{array}$ & $\begin{array}{c}\text { Metal } \\
\text { Removal } \\
\text { rate }\end{array}$ \\
\hline
\end{tabular}

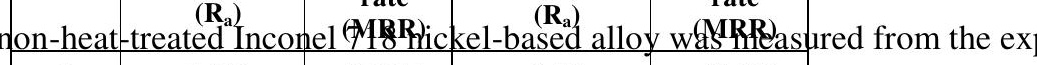

\begin{tabular}{|c|c|c|c|c|}
\hline 1. & 1.76 & 36.17 & 2.72 & 45.92 \\
\hline 2. & 1.89 & 67.40 & 3.56 & 86.95 \\
\hline 3. & 2.35 & 107.77 & 3.98 & 100.92 \\
\hline $\mathbf{4 .}$ & 2.97 & 61.62 & 3.15 & 75.95 \\
\hline $\mathbf{5 .}$ & 3.26 & 102.07 & 3.96 & 98.26 \\
\hline $\mathbf{6 .}$ & 2.07 & 62.002 & 4.53 & 90.85 \\
\hline $\mathbf{7 .}$ & 1.83 & 91.866 & 2.95 & 101.82 \\
\hline $\mathbf{8 .}$ & 2.85 & 58.136 & 3.62 & 62.35 \\
\hline $\mathbf{9 .}$ & 3.16 & 103.999 & 4.82 & 112.567 \\
\hline
\end{tabular}

The above represented values are depicted graphically in the following figure 3 . Here the blue lines represent the curve corresponds to material removal rate for non-heat-treated material. Similarly, the red lines represent the curve corresponds to material removal rate for heat-treated material. From that comparison, the material removal rate is mostly influence for heat treated material.

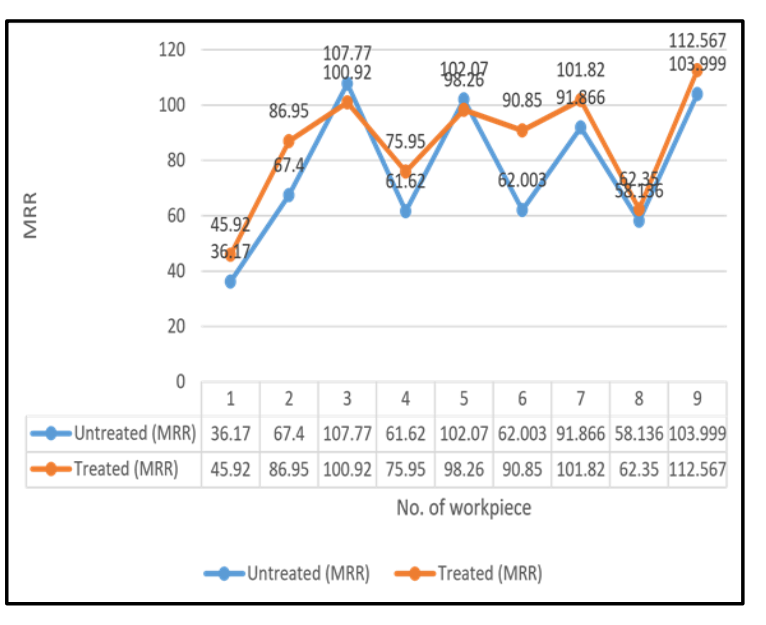

Fig 3. Comparison of Surface roughness (Ra) between treated and untreated material 


\section{E-ISSN: 2321-9637}

\section{Available online at www.ijrat.org}

The above represented values are depicted graphically in the following figure 3 . Here the blue lines represent the curve corresponds to surface roughness for non-heat-treated material. Similarly, the red lines represent the curve corresponds to material removal rate for heat-treated material. From that comparison, the surface roughness is mostly influence for heat treated material.

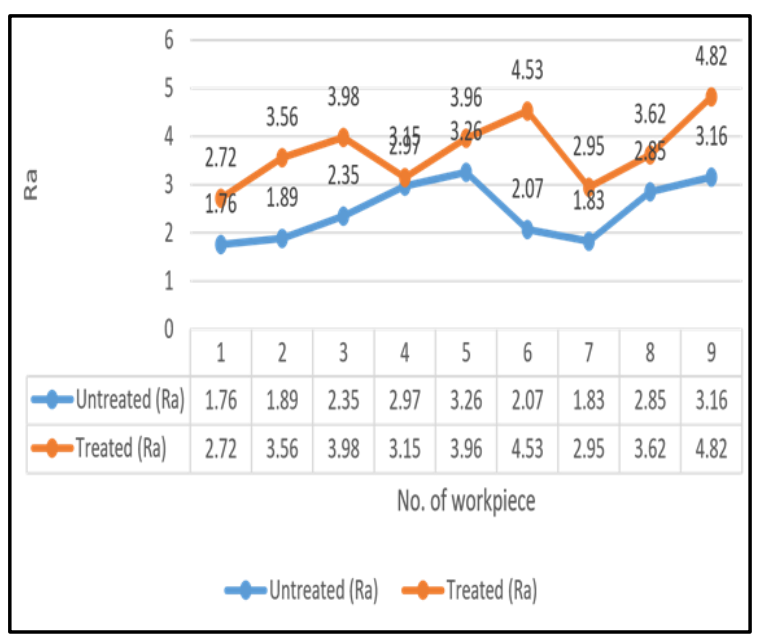

Fig 4. Comparison of metal removal rate (MRR) between treated and untreated material

\subsection{Microstructure study}

Scanning electron microscope is useful technique for the investigation of surface structure of samples. SEM has been previously used to show a clear visualization of microstructure for the underlying surface. The SEM images are taken in scanning electron microscope instrument model JSM-6610.

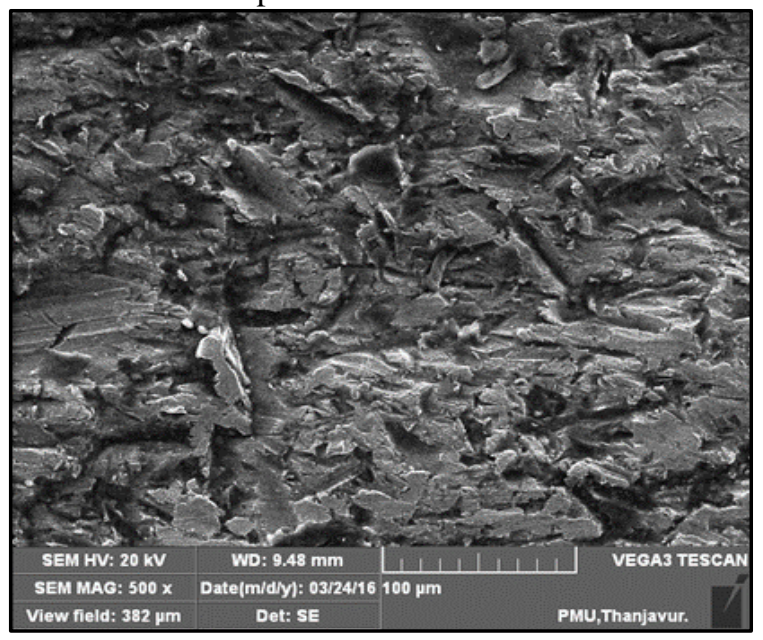

Fig 5. Microstructure of nonheat treated Inconel718

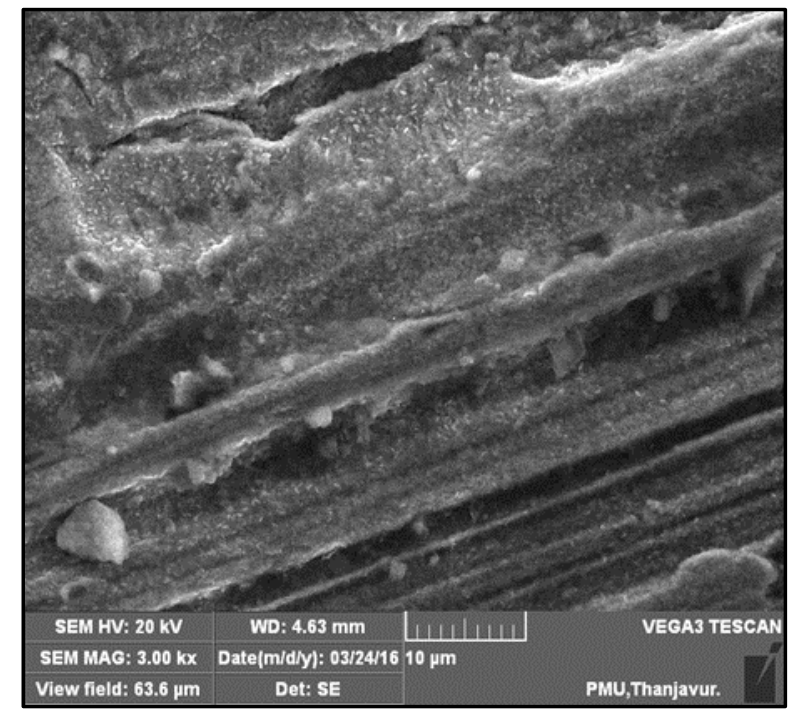

Fig 6. Microstructure of heat-treated Inconel 718

The figure 5 clearly shows the microstructure of nonheat-treated Inconel 718 nickel-based alloy. The figure 5 clearly shows the microstructure of non-heat-treated Inconel 718 nickel-based alloy.

\section{CONCLUSION}

In this work following conclusion have been made,

- Minimum surface roughness value have been predicted for the heat treated and non-heat treated Inconel 718 Nickel based alloy. Machining operation have been done using $\mathrm{CNC}$ turning Centre based on Orthogonal array.

- Maximum material removal rate for heat treated and non-heat-treated Inconel 718 Nickel based alloys have been predicted based on Orthogonal array.

- Both heat-treated and non-heat-treated material surface roughness were compared. similarly, material removal rate also compared. from that comparison Heat treated Inconel 718 have been achieved the maximum material removal rate and minimum surface roughness was achieved on heat treated Inconel 718.

- Microstructure analyses have been performed on both heat-treated and non-heat-treated Inconel 718 alloy by using scanning electron microscope.

\section{REFERENCES}

[1] Jawaid .A, et al., (2001). "Cutting performance and wear characteristics of PVD coated and uncoated carbide tools in face milling Inconel 718 aerospace alloy" Journal of Materials Processing Technology.

[2] Hasimoto .N, et al., (2003). "Microstructural analysis of ion-irradiation-induced hardening in Inconel 718" Journal of Nuclear Materials. 


\section{Available online at www.ijrat.org}

[3] Soo .S.L, et al., (2004). "3D FE Modelling of the cutting of Inconel 718" Journal of Materials Processing Technology.

[4] Arunachalam .M et al., (2004)."Residual stress and surface roughness when CBN and ceramic cutting tools" International Journal of Machine Tools \& Manufacturer.

[5] Pawade .R.S, et al., (2008). "Effect of machining parameters and cutting-edge geometry on surface integrity of high-speed turned Inconel 718" International Journal of Machine Tools and Manufacturing.

[6] Courbon .C, et al., (2009)."Investigation of machining performance in high-pressure jet assisted turning of Inconel 718" International Journal of Machine Tools \& Manufacture.

[7] Abdullah Kurt, et al., (2009)."Modelling of the cutting tool stresses in machining of Inconel 718 using artificial

[8] Tabernero .I, et al., (2011)."Evaluation of the mechanical properties of Inconel 718 components built by laser cladding" International Journal of Machine Tools \& Manufacture.

[9] Pusavec .F, et al., (2011). "Surface integrity in cryogenic machining of nickel based alloyInconel 718" Journal of Materials Processing Technology.

[10] Gao Dong, et al., (2011). "Study of cutting deformation in machining nickel-based alloy Inconel 718" International Journal of Machine Tools \& Manufacture. Nowotnik .A, et al., (2012). "Mechanical properties of hot deformed Inconel 718 and $\mathrm{X}$

[11] 750" Journal of Achievements in Materials and Manufacturing Engineering.

[12] Bushlya .V, et al., (2012)."Effects of cutting conditions on machinability of super alloy Inconel 718 during high speed turning with coated and uncoated PCBN tools".

[13] Antonio Del Prete, et al., (2013). "Finite element simulation of machining Inconel 718 alloy including microstructure changes" International Journal of Mechanical Science.

[14] Lohithaksha M Maiyara, et al., (2013). "Numerical simulation of machining nickelbased alloys".

[15] Jafarian .F, et al., (2014). "Optimization of machining parameters for end milling of Inconel 718 super alloy using Taguchi based grey relational analysis" International Conference on Design and Manufacturing.

[16] FranciPusavec, et al., (2014). "Finite element simulation of machining Inconel718 alloy including microstructure Changes".

[17] Diaz-Alvarez .J, et al., (2014). “Sustainable Machining of High Temperature Nickel Alloy
- Inconel 718: Part Chip Breakability and Optimization” Journal of Cleaner Production.

[18] Li. W, et al., (2014)."Numerical analysis of thermo mechanical phenomena influencing tool wear in finishing turningofInconel718"

[19] Arrazola .P.J, et al., (2014).“Effect Tool Wear during End Milling on the Surface

[20] Integrity and Fatigue Life of Inconel 718" International Conference on High Performance Cutting.

[21] Vaclav Schornika, et al., (2015). "On the machining induced residual stresses in IN718 nickel-based alloy: Experiments and predictions with finite element simulation".

[22] Yigit M. Arisoy, et al., (2016)."The interference of working environment and cutting conditions on milling nickel-based super alloy with carbide tools". 